\title{
Is pain from mammography reduced by the use of a radiolucent MammoPad? Local experience in Hong Kong
}

\author{
Helen HL Chan *, Gladys Lo, Polly SY Cheung
}

\section{A B S T R A C T}

Introduction: Screening mammogram can decrease the mortality of breast cancer. Studies show that women avoid mammogram because of fear of pain, diagnosis, and radiation. This study aimed to evaluate the effectiveness of a radiolucent pad (MammoPad; Hologic Inc, Bedford [MA], US) during screening mammogram to reduce pain in Chinese patients and the possibility of glandular dose reduction.

Methods: This case series was conducted in a private hospital in Hong Kong. Between November 2011 and January 2012, a total of 100 Chinese patients were recruited to our study. Left mammogram was performed without MammoPad and served as a control. Right mammogram was performed with the radiolucent MammoPad. All patients were then requested to complete a simple questionnaire. The degree of pain and discomfort was rated on a $0-10$

This article was published on $22 \mathrm{Apr}$ 2016 at www.hkmj.org. numeric analogue scale. Significant reduction in

discomfort was defined as a decrease of $10 \%$ or more.
Results: Of the 100 patients enrolled in this study, $66.3 \%$ of women reported at least a $10 \%$ reduction in the level of discomfort with the use of MammoPad. No statistical differences between age, breast size, and the level of discomfort were found.

Conclusion: The use of MammoPad significantly reduced the level of discomfort experienced during mammography. Radiation dose was also reduced.

\begin{tabular}{l} 
Hong Kong Med J 2016;22:210-5 \\
\hline DOI: 10.12809/hkmj154602 \\
${ }^{1}$ HHL Chan *, FHKCR, FHKAM (Radiology) \\
${ }^{1}$ G Lo, FHKCR, FHKAM (Radiology) \\
${ }^{2}$ PSY Cheung, FCSHK, FHKAM (Surgery) \\
${ }^{1}$ Department of Diagnostic and Interventional Radiology, Hong Kong \\
Sanatorium \& Hospital, Happy Valley, Hong Kong \\
${ }^{2}$ Private practice, Hong Kong \\
${ }^{*}$ Corresponding author: chanhlh@yahoo.com
\end{tabular}

New knowledge added by this study

- Pain and discomfort associated with mammography is reduced with the use of MammoPad.

- The glandular dose for mammography is also reduced.

Implications for clinical practice or policy

MammoPad is now used in all our patients. There are fewer complaints about pain during mammography.

\section{Introduction}

Screening mammography is the only known scientifically proven method that can decrease the mortality of breast cancer. ${ }^{1,2}$ Although most women are informed of the importance of mammography, a significant number avoid this screening procedure. The three most common reasons given are fear of pain, fear of the mammogram results, and fear of radiation.

Among these three reasons, pain and discomfort appear to be the most common, especially in those with a poor experience. ${ }^{3}$ Although most pain occurs during breast compression, reducing compression by the technician had no significant effect on the discomfort of mammography. Studies have quoted different methods to relieve patient anxiety and to reduce pain and discomfort during the procedure. These included a thorough explanation of the procedure, ${ }^{4}$ topical application of $4 \%$ lidocaine gel to the skin of the chest before mammography, ${ }^{5}$ self-controlled breast compression during mammography, ${ }^{6}$ and the use of a radiolucent pad (MammoPad; Hologic Inc, Bedford [MA], US) during mammography. ${ }^{7,8}$ Oral acetaminophen and ibuprofen were shown to be of no significant effect in relieving discomfort during mammography. Poulos and Rickard ${ }^{9}$ reported that decreasing the compression force did not significantly reduce discomfort.

Asian patients might have more fibroglandular tissue in their breasts that thus appear to have a higher density on screening mammogram. Whether or not they experience more discomfort during mammography is unknown. MammoPad is a soft, compressible cushion that provides a softer and warmer surface for taking mammography. We believe it may improve compliance with mammography among Asian patients. We performed a prospective study to evaluate the effectiveness of MammoPad used during screening mammogram to reduce pain 
in Asian patients. The possibility of glandular dose reduction was also assessed.

\section{Methods}

Between November 2011 and January 2012, a total of 100 patients were recruited to our study. The inclusion criteria included Chinese women who were asymptomatic and referred for routine breast screening. Patients prescribed regular oral contraceptive pills and those with a family history of breast cancer were also included in our study. There was no age limitation. The included participants were 32 to 70 years old, with a mean age of 49.7 ( \pm standard deviation, 7.3) years. Women with known breast cancer, who presented with breast lump or had prior breast surgery, were excluded. After obtaining informed consent, screening mammogram was performed with the standard craniocaudal (CC) and mediolateral oblique (MLO) views. For each patient, the left breast was imaged without MammoPad and served as a control. The MammoPad was then placed on the surface of the digital detector of the mammographic equipment (Inspiration/Novation, Siemens, Germany) and the right mammogram was performed (Figs 1 and 2). The level of compression was determined by the experienced mammographic

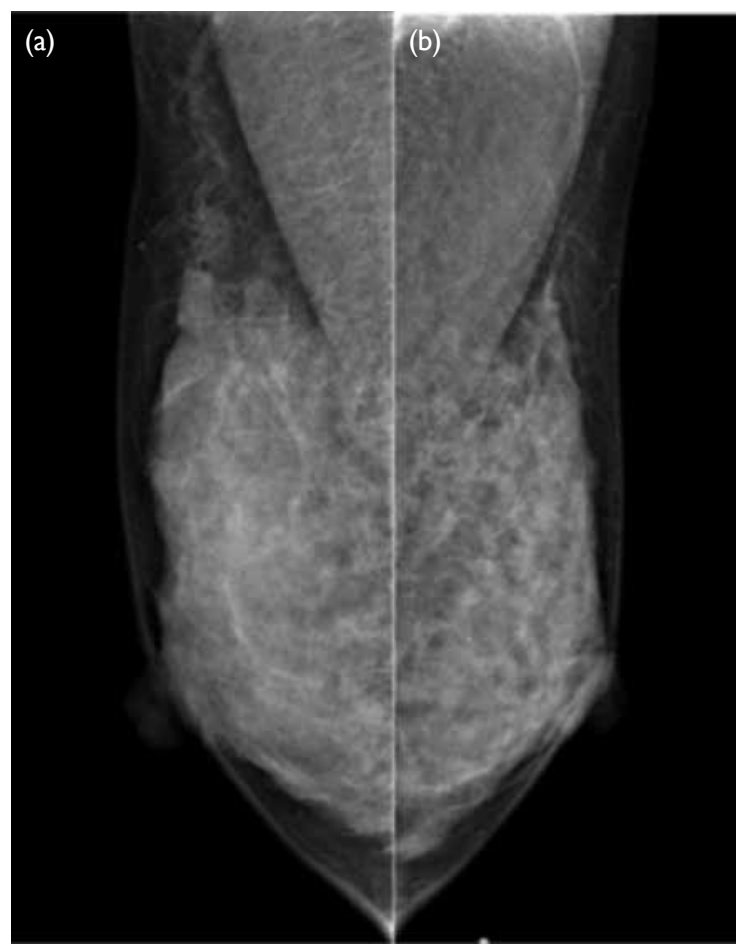

FIG I. Image quality between the right and left mammogram in dense breast

(a) The right mammogram is performed with a pad and (b) the left mammogram is performed without a pad and serve as the control. No significant change in image quality is shown between the right and left mammogram in dense breast

\section{可透X光射線的乳房攝影軟熱（MammoPad）是 否可以減輕乳房X光造影檢查的過程中因壓迫乳 房而造成的疼痛感 ? 香港的經驗}

\author{
陳羲璘、羅吳美英、張淑儀
}

引言：乳房X光造影篩選檢查可降低乳癌死亡率, 可是研究顯示女性 往往會因為害怕疼痛、診斷結果和檢查過程中接觸的輻射而避免進行 乳房X光造影檢查。本研究探討華籍病人在乳房X光造影檢查中使用 MammoPad來減輕疼痛感的成效, 以及減低乳腺輻射劑量的可能性。

方法：本病例系列於香港一間私營醫院內進行。在 2011 年 11 月至 2012 年1月期間共招募了 100 名華籍患者參與本研究。乳房X光造影檢 查的過程中, 右乳房使用了可透X光射線的MammoPad, 而左乳房則 沒有使用MammoPad以作為對照。所有患者在檢查後必須填寫一份簡 單的問卷, 在數值評分量表 0 至 10 分按着其疼痛和不適程度來評分。 當不適程度減少 $10 \%$ 或以上便被定義為明顯的減輕不適。

結果：在100名參與者中, $66.3 \%$ 的參與者在使用MammoPad後, 其 不適程度減少了 $10 \%$ 或以上。年齡和乳房的大小與不適程度無明顯的 關聯。

結論：在乳房X光檢查中使用MammoPad明顯能減輕不適感, 亦可減 低乳腺輻射劑量。 technician. On completion of the procedure, all patients were requested to complete a simple questionnaire (Appendix). The degree of pain and discomfort (including coldness and hardness of the mammogram compression device) was assessed by a 0-10 numeric analogue scale. Three patients refused to participate in the study.

The image quality of the mammograms with and without MammoPad was assessed by two experienced radiologists who had mammographic training (one radiologist had $>20$ years of and another radiologist $>10$ years of mammography reading experience). The two radiologists were blinded as to which side of the mammogram was performed with and without MammoPad. Since the MammoPad was radiolucent, its presence was not evident on the mammogram.

The mammographic assessment was divided into five categories:

(1) Symmetrical on both sides with satisfactory diagnostic image quality;

(2) Quality of right mammogram image slightly better than the left mammogram but with diagnostic accuracy unaffected;

(3) Quality of left mammogram image slightly better than the right mammogram but with diagnostic accuracy unaffected;

(4) Quality of right mammogram image much better than the left mammogram, affected the diagnostic accuracy, and required repeated mammogram; and 


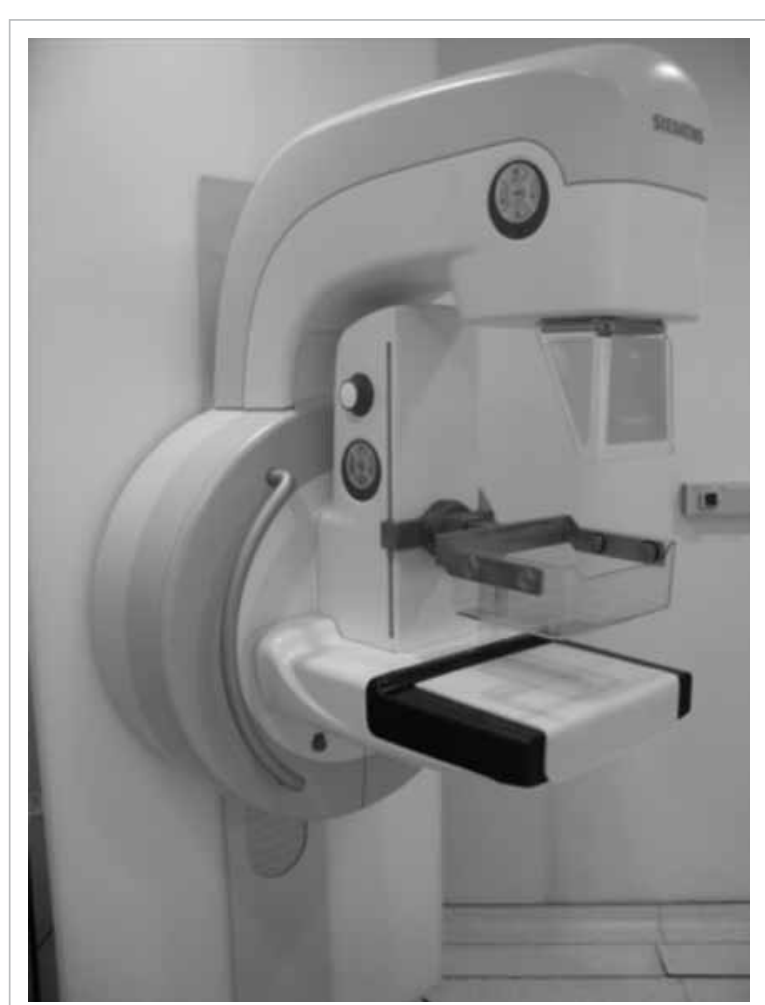

FIG 2. The use of MammoPad on the mammographic equipment

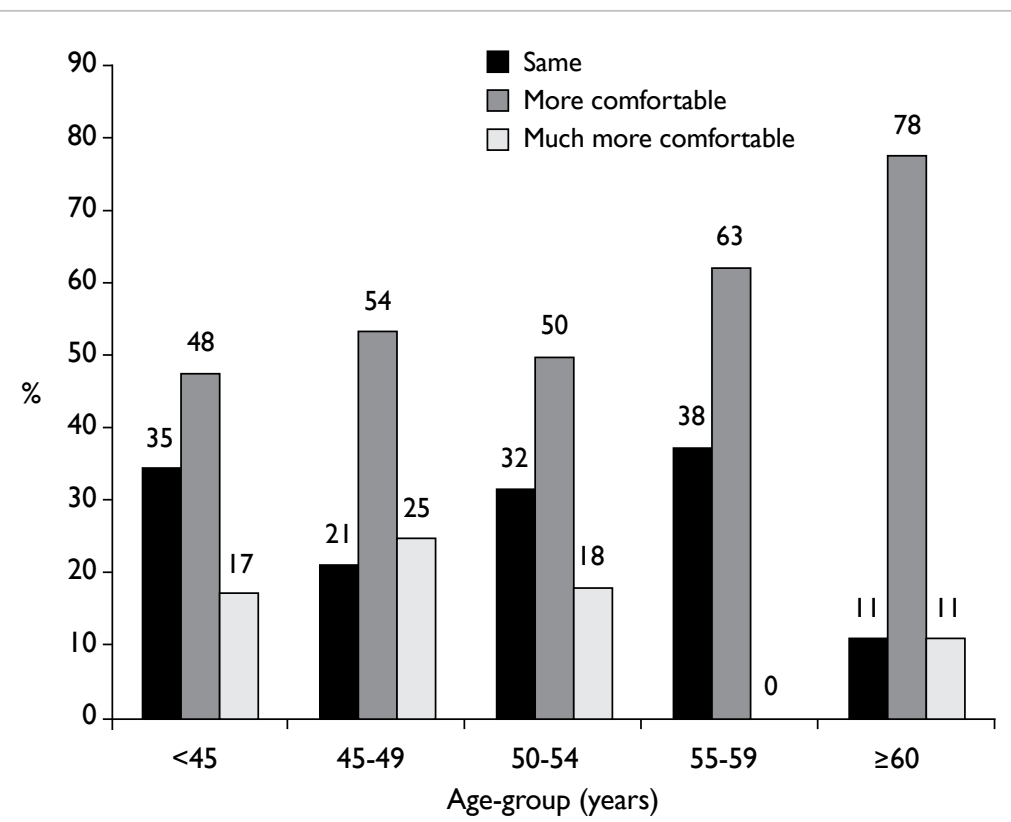

FIG 3. Association between age and comfort during mammography

There was no statistical significance between age and comfort during mammography $(P=0.664)$
Any disagreement about the findings was resolved through consensus between the radiologists.

\section{Statistical analysis}

Significant reduction in discomfort of the mammography was defined as a decrease in discomfort by $10 \%$ or more. The mean differences in continuous variables between the mammograms with and without a pad were tested by paired sample $t$ test. The differences in the percentage of comfort between groups in density, size, and age were tested by Chi squared test. A two-tailed $\mathrm{P}$ value of $<0.05$ was considered statistically significant.

\section{Results}

\section{Image quality}

Among the mammograms compared, $92 \%$ of the images from the two groups with or without MammoPad had comparable image quality (Fig 1 ). Only $4 \%$ of images from the group without MammoPad were found to have better image quality. Another $4 \%$ of the images from the group with MammoPad were noted to have better image quality. In the $4 \%$ of image groups with image quality differences (either right side better than the left side or vice versa), two radiologists did not consider diagnostic accuracy to be affected. The patients with image quality differences of the right and left side had follow-up mammograms without MammoPad performed 1 year later. There was no mammographic evidence of malignancy in these patients.

\section{For pain and discomfort reduction}

The Table shows the comparisons in pain reduction and other measures between the mammograms with and without a pad. Using paired sample $t$ test, the mean ( \pm standard deviation) scores for pain $(5.7 \pm$ 2.5 vs $4.2 \pm 1.8)$, coldness $(4.0 \pm 2.2$ vs $2.2 \pm 2.1)$, hardness $(3.6 \pm 2.4$ vs $2.0 \pm 2.1)$, and overall feeling $(4.1 \pm 2.3$ vs $2.6 \pm 2.1)$ were significantly higher in the group without MammoPad than the group with MammoPad (all $\mathrm{P}<0.001$ ). The thickness was higher in the group with MammoPad when compared with the group without MammoPad in both the $\mathrm{CC}$ view $(57.8 \pm 13.8 \mathrm{~mm}$ vs $53.1 \pm 13.0 \mathrm{~mm} ; \mathrm{P}<0.001)$ and MLO view $(54.2 \pm 16.6 \mathrm{~mm}$ vs $50.9 \pm 16.4 \mathrm{~mm}$; $\mathrm{P}=0.019)$.

Among the 100 patients, 90 of them had previously undergone mammography of whom 64 (71.1\%) reported the mammogram with a pad to be 'more comfortable' or 'much more comfortable' than prior studies without a pad. Only 26 (28.9\%) patients reported that the level of discomfort for mammogram with MammoPad was the same as prior studies. There was no association between patient age and comfort during mammography (Chi squared value $=5.81$, degrees of freedom $[\mathrm{df}]=8$, 
$\mathrm{P}=0.664$; Fig 3 ). Patients with less breast density were more likely to report 'much more comfortable' than those patients with high breast density (Chi squared value $=10.3[\mathrm{df}=2], \mathrm{P}=0.006$; Fig 4). There was no statistically significant association between breast size and comfort during mammography (Chi squared value $=4.68[\mathrm{df}=4], \mathrm{P}=0.322$; Fig 5). All patients preferred using MammoPad in future mammography.

\section{For dosage reduction}

The mean glandular dose was higher in the group without MammoPad than the group with MammoPad in both views $(1.11 \pm 0.44 \mathrm{mGy}$ vs 1.06 $\pm 0.38 \mathrm{mGy}$ for CC view, and $1.08 \pm 0.43 \mathrm{mGy}$ vs $1.01 \pm 0.36 \mathrm{mGy}$ for MLO view). For the group with MammoPad, there was a $4.5 \%$ decrease in dose for the $\mathrm{CC}$ view and $6.5 \%$ decrease in dose for the MLO view. The statistical significance was $\mathrm{P}=0.01$ and 0.001 , respectively (Table).

\section{For compression force}

There was no statistically significant difference in the mean compression force in the two groups in the $\mathrm{CC}$ view $(80.1 \pm 27.1 \mathrm{~N}$ vs $77.2 \pm 29.3 \mathrm{~N}$; $\mathrm{P}=0.094)$. Reduced compression force in the MammoPad group was noticed in the MLO view $(82.0 \pm 37.7 \mathrm{~N}$ vs $86.0 \pm 38.5 \mathrm{~N} ; \mathrm{P}=0.037$ ) [Table].

\section{Discussion}

Breast cancer is the third leading cause of cancer death among females in Hong Kong, after colorectal and lung cancers. ${ }^{10}$ In 2013, a total of 596 women died from breast cancer, accounting for $10.5 \%$ of all cancer deaths in females. ${ }^{10}$ Screening mammogram is proven to be effective in the early detection of breast cancer. Unfortunately, the utilisation of screening mammogram in Hong Kong is limited, partly because there is no government-subsidised mammographic screening programme. Another important factor is the discomfort experienced during mammography.

Various studies have attempted to reduce the pain and discomfort associated with mammography. The most promising method to date appears to be the radiolucent MammoPad. Tabar et $\mathrm{al}^{7}$ reported that two thirds of women experienced a significant reduction in pain when the radiolucent cushions were used during mammography. Markle et $\mathrm{al}^{8}$ reported that use of a radiolucent cushion reduced discomfort during screening mammogram in $73.5 \%$ of patients.

In our study, we confirmed that the image quality of the mammograms was unaffected by the presence of the MammoPad. After review by the radiologists, diagnostic accuracy was considered unaffected in the $4 \%$ image groups with image

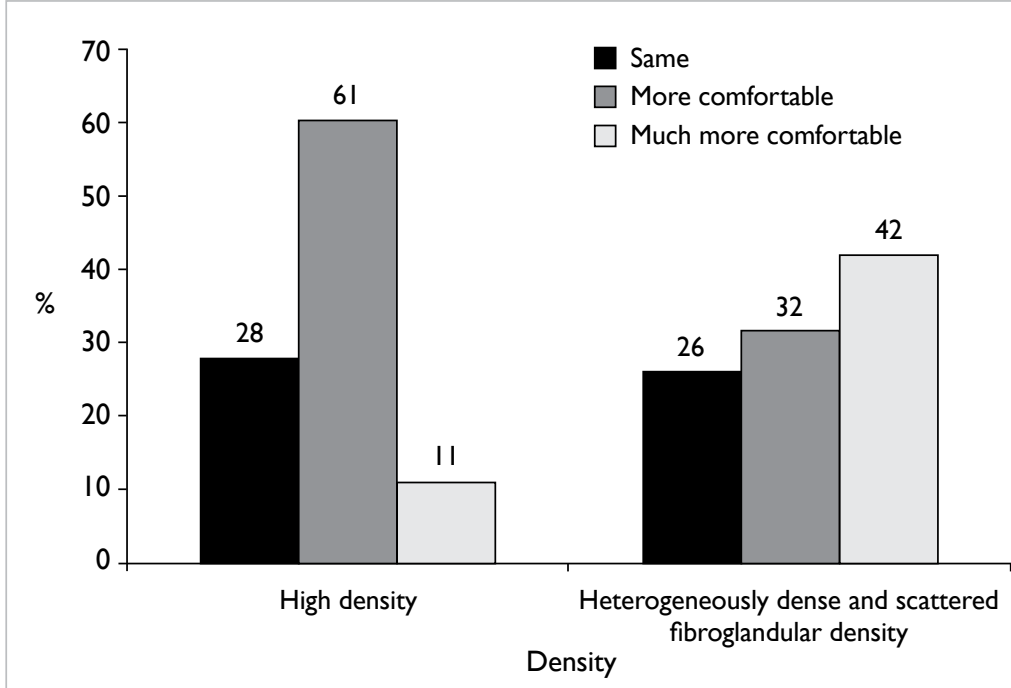

FIG 4. Comparison of patients with less breast density and those with high breast density

Patients with less breast density were more likely to report 'much more comfortable' than patients with high breast density $(\mathrm{P}=0.006)$

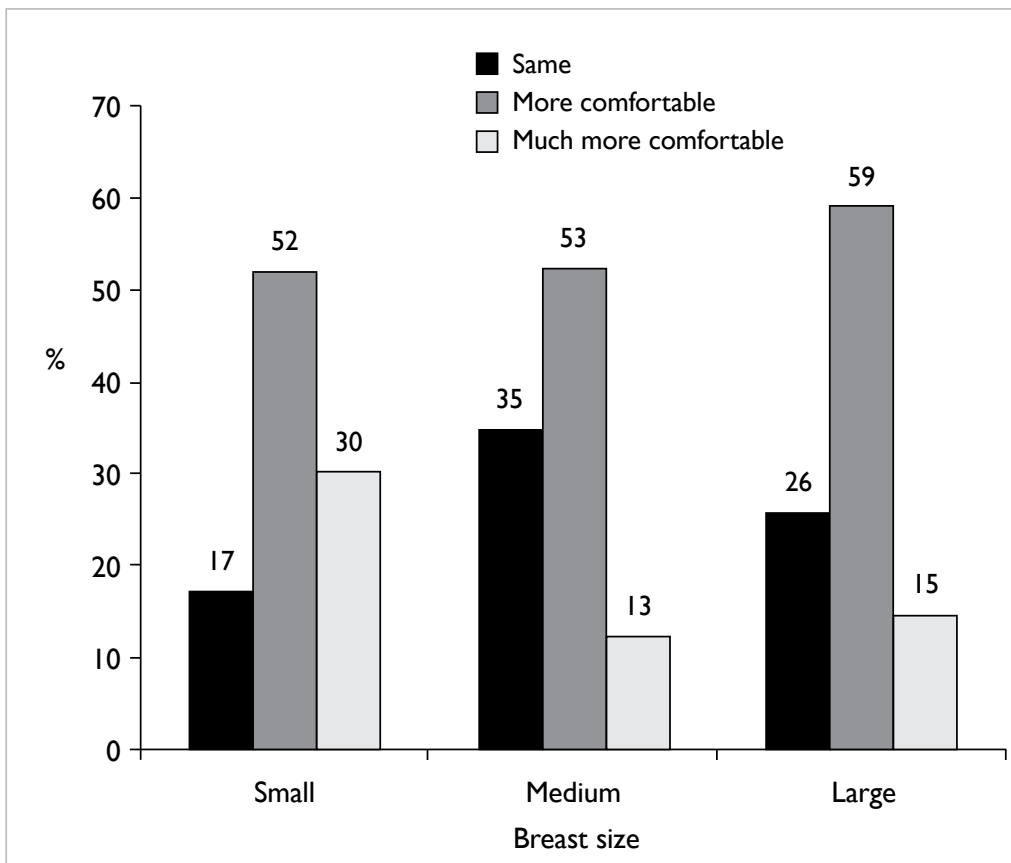

FIG 5. Association between breast size and comfort during mammography There was no statistical significance between the breast size and the comfort during mammography $(P=0.322)$

quality differences (either right side better than the left or vice versa). The difference in image quality was probably secondary to asymmetrical fibroglandular tissue thickness in both breasts. In all, $66.3 \%$ of our patients reported at least a $10 \%$ reduction in the level of discomfort with the use of MammoPad. This 
TABLE. Comparison of pain and discomfort score, compression force, and dose parameters for mammograms with and without MammoPad

\begin{tabular}{|c|c|c|c|c|}
\hline & \multicolumn{2}{|c|}{ Mean \pm standard deviation } & \multirow{2}{*}{$\begin{array}{l}\text { T value (degrees } \\
\text { of freedom) }\end{array}$} & \multirow[t]{2}{*}{$P$ value } \\
\hline & Without MammoPad & With MammoPad & & \\
\hline Pain & $5.7 \pm 2.5$ & $4.2 \pm 1.8$ & $8.11(99)$ & $<0.001$ \\
\hline Coldness & $4.0 \pm 2.2$ & $2.2 \pm 2.1$ & $11.26(99)$ & $<0.001$ \\
\hline Hardness & $3.6 \pm 2.4$ & $2.0 \pm 2.1$ & $9.41(99)$ & $<0.001$ \\
\hline Overall feeling & $4.1 \pm 2.3$ & $2.6 \pm 2.1$ & $9.76(99)$ & $<0.001$ \\
\hline \multicolumn{5}{|l|}{ Mediolateral oblique view } \\
\hline Thickness (mm) & $50.9 \pm 16.4$ & $54.2 \pm 16.6$ & $2.39(99)$ & 0.019 \\
\hline Force $(\mathrm{N})$ & $86.0 \pm 38.5$ & $82.0 \pm 37.7$ & $-3.85(99)$ & 0.037 \\
\hline Glandular dose (mGy) & $1.08 \pm 0.43$ & $1.01 \pm 0.36$ & $-3.31(99)$ & 0.001 \\
\hline \multicolumn{5}{|l|}{ Craniocaudal view } \\
\hline Thickness (mm) & $53.1 \pm 13.0$ & $57.8 \pm 13.8$ & $6.08(99)$ & $<0.001$ \\
\hline Force $(\mathrm{N})$ & $77.2 \pm 29.3$ & $80.1 \pm 27.1$ & $1.69(99)$ & 0.094 \\
\hline Glandular dose (mGy) & $1.11 \pm 0.44$ & $1.06 \pm 0.38$ & $-2.64(99)$ & 0.010 \\
\hline
\end{tabular}

finding was comparable with the study performed by Tabar et al. ${ }^{7}$ In addition, there was no obvious correlation between age, breast size, and level of discomfort. Reduced compression force in the group with MammoPad was noticed in the MLO view, but not in the CC view.

Unlike the study performed by Dibble et al, ${ }^{11}$ we encountered no problem with inadequate positioning for the mammograms. This may have been because our technicians were well-trained in the use of the MammoPad prior to study commencement. No mammograms required repetition.

With the use of MammoPad, Markle et $\mathrm{al}^{8}$ also reported a $4 \%$ decreased dose in the $\mathrm{CC}$ view, but not the MLO view. In our study, there was a $4.5 \%$ decrease in dose for the CC view and $6.5 \%$ decrease in dose for the MLO view. These data were statistically significant $(\mathrm{P}<0.05)$. With the use of the MammoPad, the compression on breast tissue may be more evenly distributed and account for the dose reduction.

Although the improved comfort while using the MammoPad and the dose reduction during mammography are encouraging, our study has several limitations. First, there might have been patient selection bias. This study was performed in a private hospital on Hong Kong Island. There were no similar data available from public hospitals elsewhere in Hong Kong so comparison was not possible. In view of the small sample size, the results might not be representative of the whole screening population. As a result, there might have been an inherent patient selection bias. This selection bias might be minimised if a larger and representative sample could be obtained. Second, since there is no routine breast cancer screening programme in Hong Kong, patients in this study were self-selected and might be more motivated to undergo mammogram or be more informed about such procedure. This might in turn affect the pain and discomfort perception and subsequent scores. In addition, the scoring system for pain, coldness, and hardness was a 0-10 numeric analogue scale system, which is a subjective scoring system. Patient anxiety may result in a higher pain score, and thus, a potential measurement bias might exist. A thorough explanation before performing the mammogram might help to reduce this bias.

The MammoPad was a single-use device with obvious hygienic and safety advantages. In the United States, the MammoPad can be recycled, although this cannot be achieved in our unit at present. We might explore the possibility of recycling the device in future to decrease the environmental impact.

\section{Conclusion}

The use of MammoPad significantly reduced the level of discomfort during mammography. This should improve compliance with initial and followup mammography. In addition, we demonstrated radiation dose reduction in both CC and MLO mammograms, which is another important benefit of using MammoPad. We recommend the use of MammoPad for screening mammography in all our patients.

\section{Acknowledgements}

The authors thank Betty ML Hung and Carmen KM Lam for their assistance in preparation of the questionnaires and data analysis. 


\section{Appendix}

Additional material related to this article can be found on the HKMJ website. Please go to <http:// www.hkmj.org>, and search for the article.

\section{Declaration}

All authors have disclosed no conflicts of interest.

\section{References}

1. Weedon-Fekjær H, Romundstad PR, Vatten LJ. Modern mammography screening and breast cancer mortality: population study. BMJ 2014;348:g3701.

2. Broeders M, Moss S, Nyström L, et al. The impact of mammographic screening on breast cancer mortality in Europe: a review of observational studies. J Med Screen 2012;19 Suppl 1:14-25.

3. Elwood M, McNoe B, Smith T, Bandaranayake M, Doyle TC. Once is enough-why some women do not continue to participate in a breast cancer screening programme. $\mathrm{N} \mathrm{Z}$ Med J 1998;111:180-3.

4. Shrestha S, Poulos A. The effect of verbal information on the experience of discomfort in mammography. Radiography 2001;7:271-7.

5. Lambertz CK, Johnson CJ, Montgomery PG, et al. Premedication to reduce discomfort during screening mammography. Radiology 2008;248:765-72.

6. Kornguth PJ, Rimer BK, Conaway MR, et al. Impact of patient-controlled compression on the mammography experience. Radiology 1993;186:99-102.

7. Tabar L, Lebovic GS, Hermann GD, Kaufman CS, Alexander C, Sayre J. Clinical assessment of a radiolucent cushion for mammography. Acta Radiol 2004;45:154-8.

8. Markle L, Roux S, Sayre JW. Reduction of discomfort during mammography utilizing a radiolucent cushioning pad. Breast J 2004;10:345-9.

9. Poulos A, Rickard M. Compression in mammography and the perception of discomfort. Australas Radiol 1997;41:247-52.

10. Hong Kong Cancer Registry. Top ten cancers in 2013. Available from: http://www3.ha.org.hk/cancereg/ Statistics.html. Accessed Mar 2016.

11. Dibble SL, Israel J, Nussey B, Sayre JW, Brenner RJ, Sickles EA. Mammography with breast cushions. Womens Health Issues 2005;15:55-63. 